Artículo de Reflexión

A puntes del CEN ES

ISSN 0120-3053

Volumen 32 - №. 55

Enero - Junio de 2013

Págs. 9-31

\title{
Estructuralismo latinoamericano
} y neomarxistas: el origen del proceso de subdesarrollo de la periferia

Latin American structuralism and neomarxists: the origin of underdevelopment process of the periphery

Fahd Boundi Chraki*

Fecha de recepción: 12 de enero de 2012

Nueva versión: 10 de junio de 2012

Fecha de aprobación: 25 de septiembre de 2012

Licenciado en Ciencias Económicas y máster en Economía Internacional y Desarrollo, de la Universidad Complutense de Madrid. España. Investigador del Círculo de Investigación para el Desarrollo y la Cooperación de Madrid (CIIDYC), Madrid, España. Correo electrónico: fahdbc@gmail.com 


\title{
Resumen
}

Este trabajo pretende establecer un análisis comparativo entre la escuela estructuralista y la escuela neomarxista, para de este modo recuperar el antiguo debate sobre qué es el desarrollo. Para tal propósito se llevará a cabo una revisión de literatura que partirá de las influencias de los clásicos y Marx en la economía del desarrollo. Asimismo, se rescatarán las aportaciones de varias de las figuras destacadas de cada escuela, con el fin de ir hilando las conexiones teóricas entre ambos enfoques de la economía del desarrollo. Además, se incidirá en el concepto de desarrollo, el origen del subdesarrollo de la periferia, las barreras hacia el desarrollo y las estrategias de desarrollo defendidas por estructuralistas y neomarxistas.

Palabras clave: desarrollo, crecimiento, capitalismo, estado, proceso, acumulación.

Clasificación JEL: A13, B24, N00, P16

\begin{abstract}
This paper seeks to establish a comparative analysis between structuralist and neo-marxists, to thereby recover the old debate about what is development. For this purpose, through a literature review that will depart from the influences of the classics and $\mathrm{M}$ arx in development economics. As well, it will recove the contributions of several prominent figures from each school in order to trace the theoretical connections between the two approaches to development economics. In addition, it will analyse the concept of development, the origin of the underdevelopment of the periphery, the barriers to development and development strategies advocated by structuralists and neo-marxists.
\end{abstract}

Keywords: development, growth, capitalism, state, process, accumulation.

JEL Classification: A13, B24, N00, P16 


\section{INTRODUCCIÓN}

Establecer un análisis comparativo de las escuelas neomarxista y estructuralista de la economía del desarrollo, plantea la necesidad de llevar a cabo un breve análisis histórico de las contribuciones de los clásicos y la crítica de la economía política de Karl Marx. Desentrañar el cuerpo teórico de los clásicos resulta, a priori, más sencillo que la crítica a la economía política de Marx, en tanto que es difícil referirse a la obra del artífice del socialismo científico como un cuerpo teórico e intelectual homogéneo y monolítico. Comprendamos que la evolución de Marx es, en todos los sentidos, magna, al desprenderse de su obra completa el origen de la formación del modo de producción capitalista. Así pues, el análisis marxiano presume un amplio estudio sistémico que va más allá de los postulados prestablecidos por la teoría clásica.
Varios de estos postulados gravitan alrededor de los principios clásicos sujetos al laissez-faire y la mano invisible defendidos por Adam Smith; para Adam Smith, el mercado es el mejor asignador de recursos, en tanto que el simple ejercicio de intercambio mercantil supone un beneficio mutuo para los diferentes sujetos implicados en las actividades económicas. Asimismo, el análisis del economista clásico recoge la influencia de los fisiócratas franceses, en especial, las aportaciones de François Quesnay y su Tableau Économique.

Mas es importante señalar que la gran aportación de Quesnay en el Tableau Économique es esencial para comprender los mecanismos y engranajes de la economía internacional, en tanto que el concepto de producto neto de Quesnay representa un potente instrumento de análisis del proceso de acumulación de capital. 
Para Quesnay, el producto neto, o excedente, se establece como la diferencia entre los diferentes valores de usos dirigidos al consumo productivo y los valores de uso dirigidos al producto social; por tanto, el excedente es el resultado de la diferencia entre el producto social y el consumo productivo. Si bien es cierto que Adam Smith impugnó el aserto fisiócrata sobre que el único sector productivo que permite la aparición del producto neto es la industria agrícola, es consabido que el economista clásico pudo construir su teoría de la acumulación de capital a partir del concepto de excedente de Quesnay. Para ello, el economista escocés establece un modelo formado por terratenientes, capitalistas y asalariados; en este modelo, la distribución de la renta favorece a los terratenientes y capitalistas, traduciéndose en la apropiación del excedente por parte de éstos. De este modo, los propietarios de los medios de producción (terratenientes y capitalistas) serán quienes tengan la capacidad de acumular los beneficios que posteriormente darán lugar a la acumulación de capital y la reinversión de parte del excedente al consumo productivo; esto es, la reinversión permitirá el aumento del producto social y el excedente, ergo, la reproducción ampliada de capital será resultado de la inversión productiva. Para que sea posible la ampliación del excedente, Adam Smith señala que parte de los beneficios deben convertirse en ahorro, lo que permitirá en el largo plazo la inversión que consienta la reproducción ampliada del capital.
Sin embargo, el modelo smithiano incide en el papel vital de la división del trabajo en el proceso de acumulación de capital. La división del trabajo requiere la especialización de la fuerza de trabajo para, de este modo, poder incrementar la productividad, el producto social y el excedente. Se desprende, por tanto, una visión productivista en La riqueza de las naciones, ergo, para que exista crecimiento y desarrollo económico es importante combinar los factores productivos (capital y trabajo) de la manera más eficiente posible. La importancia de la especialización de la fuerza de trabajo y la división del trabajo dotará a las naciones de la ventaja absoluta que consentirá el comercio internacional, es decir, el enfoque de Adam Smith acepta tajantemente la tesis de la monoeconomía, al considerar la existencia de mecanismos autorre-guladores de la economía. Así, el laissez-faire y la mano invisible serán los instru-mentos que regulen la economía, y por tanto, cualquier política planteada por el Estado y las administraciones públicas, será innecesaria ${ }^{1}$. Por otro lado, el legado de Adam Smith fue recogido por Ricardo con sutiles diferencias e importantes aportaciones que más tarde inspiraron a los enfoques marxiano y neoclásico; Ricardo estableció que los rendimientos de la tierra eran decrecientes, en tanto que a medida que crecía la población era necesario explotar tierras cada vez menos fértiles para la agricultura, concluyendo que la última tierra en explotar será la que demandará el mayor número

\footnotetext{
Empero, este punto debe ser matizado. Adam Smith no mostraba un absoluto rechazo al papel del Estado, como sí mostrarían a partir de 1870 los marginalistas y neoclásicos. Para Smith, el Estado era importante, en tanto éste tendría la función de realizar inversiones en infraestructuras.
} 
de horas necesarias para la producción, a consecuencia de su menor fertilidad.

Por ende, la última tierra, o tierra inferior, permitirá la aparición de la renta diferencial, ergo, será la tierra marginal donde el valor de cambio (precio) se igualará con el coste marginal. Por tanto, la tesis de la monoeconomía se vio reforzada con la teoría ricardiana de los rendimientos decrecientes de la tierra. De igual modo, en Ricardo encontramos el primer modelo del comercio internacional basado en los costes comparativos, es decir, las naciones presentarán ventaja comparativa en la producción de bienes y mercancías según su dotación de factores, lo que implica la especialización productiva. Para entender el modelo ricardiano es imperativo comprender que el objeto de Ricardo era explicar cómo pasar de las leyes de la competencia dentro de una nación a las leyes de la competencia internacional. Ricardo, quien aceptaba la Ley de Say y la neutralidad del dinero, entendía que los términos de intercambio (los precios relativos internacionales) se modificaban hasta alcanzar el equilibrio comercial entre naciones, asimismo, el modelo de Ricardo presupone que existe competencia perfecta, es decir, el mercado actúa como el perfecto asignador de recursos. De igual manera, el modelo ricardiano está sujeto a la teoría de los species-flows de
David Hume, esto es, la teoría cuantitativa del dinero ${ }^{2}$. Por ende, los precios estarán sujetos a la variación de la cantidad de dinero en circulación; las naciones menos competitivas dirigirán sus reservas de oro para importar los bienes y mercancías procedentes de los países más competitivos, ergo, en el corto plazo, los países más competitivos tienen ventaja absoluta en los bienes que exportan. Sin embargo, la teoría de los species-flows establece que un descenso de la cantidad de oro se traduce en una caída proporcional de los precios. Por tanto, el país menos competitivo se verá favorecido por la caída de los precios, al poder ofrecer los bienes y mercancías a un precio inferior. Mientras, el país más competitivo experimentará el alza de los precios tras recibir grandes cantidades de oro procedentes de las exportaciones. Así, ambas naciones se volverán igual de competitivas, desprendiéndose de esta relación el proceso de equilibrio del comercio internacional; sin embargo, cabe señalar que la posibilidad de alcanzar el equilibrio en el modelo de Ricardo se debe a la inmovilidad del factor capital a nivel internacional, es decir, el modelo ricardiano es un modelo estático que no tiene en cuenta la naturaleza dinámica de la economía capitalista. De igual modo, la visión ricardiana del comercio internacional fortalece la tesis del beneficio mutuo. Empero, Marx refuta

\footnotetext{
2 Ricardo conocía perfectamente la teoría monetaria de David Hume. Mas ésta aún no era conocida como la teoría cuantitativa del dinero. Fue Irving Fisher quien, en 1911, definió matemáticamente la relación entre cantidad de dinero y precios como la teoría cuantitativa del dinero, la cual sigue la siguiente fórmula: $\mathrm{M} \times \mathrm{V}=\mathrm{P} \times \mathrm{Y}$, donde $\mathrm{M}$, indica la masa monetaria, $V$ la velocidad de circulación, $P$ los precios e $Y$ el nivel de producto. Despejando esta relación, se puede calcular el índice de precios como: $\mathrm{P}=(\mathrm{M} \times \mathrm{V}) / \mathrm{Y}$.
} 
varios de los asertos de Adam Smith y Ricardo; el economista de Tréveris impugna la teoría valor trabajo de Adam Smith y se aleja de la visión puramente técnica de la teoría valor trabajo de Ricardo. El enfoque marxiano establece que las relaciones de producción capitalistas se sostienen en la explotación de la fuerza de trabajo por parte del capital, asimismo, dota de categorías sociales a las relaciones de producción, las cuales se materializan en los antagonismos de clase y la dicotomía capital-trabajo.

De igual forma, el enfoque marxiano reconoce como fuente del valor, el trabajo humano abstracto; la teoría objetiva del valor marxiana establece que el valor está medido por el tiempo socialmente necesario de producción, además, la fuerza de trabajo en el modo de producción capitalista tiene la naturaleza de ser una mercancía. Esto es, el trabajador recibe un salario equivalente al valor de las subsistencias para la reproducción de su fuerza de trabajo, sin embargo, este salario corresponde a una parte del valor de producción, mientras que la parte no retribuida al trabajador será expoliada por los propietarios de los medios de producción en forma de plusvalor $^{3}$. Por tanto, se desprende del análisis de Marx el rechazo a la tesis del beneficio mutuo, en tanto que las relaciones de producción se reproducen a nivel mundial a consecuencia de la naturaleza global del capitalismo. Empero, es dudoso que Marx aceptase la tesis de la monoeconomía, tal como llegó a afirmar Albert O. Hirschman, quien extrae la siguiente cita de Marx; "el país más desarrollado en el terreno industrial no hace más que señalar a quienes lo siguen por la escalera industrial la imagen de su propio futuro" (Hirshcman, 1980, p. 1057-1059). Sin embargo, el economista alemán parece ignorar el rechazo de Marx sobre su primer discernimiento en cuanto a que la nación más desarrollada podía ser el espejo para el resto de naciones; si aceptásemos esta primera idea sostenida por Marx, encontraríamos en él al precursor de Walter W. Rostow y su teoría de las etapas. En cambio, esta afirmación sería atrevida, puesto que la visión de Rostow establece que el retraso de las naciones es un estado. Por el contrario, para el economista de Tréveris en modo alguno se puede considerar el retraso de las naciones como un estado, en tanto que el desarrollo capitalista es un desarrollo desigual y combinado (Novack, 1965). Por tanto, el desarrollo social no se puede explicar como una secuencia lineal de estadios evolutivos similares entre países, debido a que estos estadios históricos se presentan combinados en los países menos desarrollados. Asimismo, a partir de 1870, Marx no concebía el desarrollo de las fuerzas productivas en los países bajo el yugo del colonialismo, puesto que la destrucción de fuerzas productivas

$3 \quad$ El valor de producción responde a la siguiente relación: $V=\mathrm{c}+v+p v$. Donde c, corresponde al capital constante (maquinaria), $v$ al capital variable (fuerza de trabajo), y $p v$ al plusvalor. 
ocasionada por la metrópoli y el carácter precapitalista de las estructuras social, política y económica de las colonias hacía inviable el desarrollo capitalista en las naciones sometidas al colonialismo. Grosso modo, podemos afirmar que el enfoque de Marx rechaza las tesis del beneficio mutuo y la monoeconomía, al mismo tiempo que se presenta como un enfoque productivista. No obstante, debemos matizar que el enfoque productivista de Marx se aleja las visiones de Adam Smith y Ricardo, en tanto que para los economistas clásicos el crecimiento es sinónimo de desarrollo, mientras que la visión marxiana establece la obligatoriedad de un vigoroso desarrollo de las fuerzas productivas que permita ampliar el excedente para su posterior socialización bajo un régimen de propiedad colectivo. De igual forma, la superación del régimen de propiedad capitalista implica la abolición del Estado burgués y la instauración del gobierno de la clase trabajadora como proceso transitorio hacia el comunismo. En conclusión, tras este breve repaso histórico de las aportaciones de los clásicos y Marx, nos imbuiremos en la labor de examinar y comparar los aportes de las escuelas neomarxista y estructuralista.

CONCEPTO DE DESARROLLO: EL FIN DEL PARADIGMA DE LA MODERNIZACIÓN

Los pioneros de la economía del desarrollo presentaban un enfoque puramente productivista, en donde el crecimiento se concebía como sinónimo de desarrollo. Ragnar Nurske analizó la existencia de un círculo vicioso de la pobreza que tenía su origen en las deficiencias estructurales reflejadas tanto por el lado de la oferta como por el lado de la demanda. Esto es, un país es pobre porque presenta bajas tasas de ahorro que no permiten financiar la inversión, asimismo, una baja tasa de acumulación imposibilita el aumento de la productividad media del trabajo. Por consiguiente, la visión del desarrollo de Nurske se encuentra fuertemente influenciada por la Teoría general de John Maynard Keynes; la intervención del Estado supone la palanca que activa los automatismos para superar el subdesarrollo, por ende, un aumento del gasto público estimulará la demanda agregada y la producción. Esta influencia keynesiana en el pensamiento de Nurske fue heredada por los estructuralistas cepalinos; Raúl Prebisch, considerado el primer gran exponente de esta escuela, exteriorizaba en sus trabajos la influencia de los principios de la demanda efectiva en tanto que para el economista argentino era condición necesaria que la participación de los asalariados en la renta nacional se elevase si se deseaba superar el subdesarrollo. Es decir, Prebisch se adscribía a la premisa de que un aumento de la participación de los ingresos de los trabajadores en la distribución del producto total tiene como efecto un mayor nivel de producto; la Teoría general establece que el aumento de la renta es mayor que el aumento del consumo, 
esto es, la propensión media a consumir es decreciente con la renta, asimismo, cuanto mayor sean los ingresos de los asalariados, mayor será su propensión marginal ahorro, en tanto que recibirán salarios por encima del precio de las subsistencias. Ahora bien, el enfoque keynesiano rechaza la premisa neoclásica de que un aumento del ahorro se traduce, per se, en un aumento de la inversión; Prebisch y los estructuralistas cepalinos concebían que el crecimiento era consecuencia de la inversión, ergo, el incremento de la inversión se traducirá en la elevación de la producción y la renta. De este modo, el aumento de la renta redundará en el crecimiento del ahorro, ergo, la identidad entre ahorro e inversión es una condición de equilibrio que se alcanzará ex post, y no ex ante, como asevera la teoría neoclásica. De igual modo, la inversión está determinada por la eficiencia marginal de capital, los tipos de interés y las expectativas de beneficios, en tanto que a diferencia de la teoría neoclásica, el enfoque keynesiano rechaza el aserto errado de que el ahorro determina la inversión. Así pues, los estructuralistas observaron que las economías más ricas presentaban mayores tasas de ahorro a consecuencia de la mayor formación bruta de capital; la inversión en las economías más ricas se veía favorecida por la alta la productividad media del trabajo, resultado de la aplicaciones de innovaciones tecnológicas y la especialización en procesos productivos intensivos en capital que garantizaban mayores salarios reales y el pleno empleo. No obstante, Prebisch, a diferencia de Nurske, no tenía una visión tan limitada del desarrollo, puesto que para el economista cepalino el desarrollo no podía ser sinónimo de crecimiento económico. Prebisch, como el resto de los estructuralistas cepalinos, rechazaba las tesis del beneficio mutuo y la monoeconomía, al no comprender el libre comercio como motor de crecimiento y desarrollo. El rechazo a las tesis del beneficio mutuo y la monoeconomía no era una seña de identidad exclusiva de los estructuralistas cepalinos, también era compartida por los autores neomarxistas. $\mathrm{Si}$ bien puede parecer que a simple vista los neomarxistas se alejan de los principios de la demanda efectiva de Keynes, existen varios puntos de conexión con los estructuralistas cepalinos y la Teoría general.

Los dos grandes pioneros de la escuela neomarxista fueron los economistas estadounidenses Paul Baran y Paul Sweezy, quienes construyeron sus teorías sobre el proceso del subdesarrollo de las economías de la periferia alrededor de la teoría del monopolio analizada en su obra cúspide, El capital monopolista, la cual se nutría de la teoría del imperialismo como etapa superior del capitalismo de Vladimir Illich Lenin. El concepto centroperiferia fue asimilado por Baran, Sweezy y el resto de economistas neomarxistas por la influencia del pensamiento de Prebisch y Celso Furtado, empero, a diferencia de los estructuralistas, la escuela neomarxista focalizó sus esfuerzos en analizar las consecuencias de la centralización y concentración del capital a escala mundial. 
No obstante, el concepto de desarrollo no se aleja en demasía del concepto propuesto por los cepalinos, en tanto que el análisis de Keynes, tal como afirmaba Joan Robinson, "presenta afinidades con el de los economistas clásicos, y por lo tanto con Marx, y no con la tradición que heredó de Marshall" (Robinson, 1976, p. 8). Además, la economista de Cambridge no dudó en afirmar que el origen de los principios de la demanda efectiva se encontraba en los diferentes volúmenes de El Capital de Marx:

Hay efectivamente muchos indicios en El Capital de una teoría de la demanda efectiva. Los discípulos de Marx pudieron haberla formulado antes de que Keynes y Kalecki la aprendieran a partir de los hechos brutales de la gran crisis, pero no lo hicieron. Los marxistas declarados saludaron en Inglaterra la Teoría general con los consabidos motes de finanzas sesudas. El elemento "keynesiano" en Marx era poco conocido (Robinson, 1968, p. 19).

Así, a las afirmaciones de Fernando Henrique Cardoso no parece faltarles razón al "acusar" a los estructuralistas cepalinos de presentar planteamientos con "obvias raíces en el pensamiento económico clásico y en el marxismo, y están empapados en un lenguaje keynesiano" (Cardoso, 1977, p. 38). Por otro lado, las afirmaciones de Robinson tienen su sostén en las aportaciones de Michal Kalecki, quien a través de los esquemas de reproducción ampliada de
El Capital, llegó a muchas de las conclusiones presentes en la Teoría general de Keynes. Si bien los trabajos de Keynes y Kalecki se caracterizan por la impugnación de los principios neoclásicos sujetos a la Ley de Say, cabe señalar que Kalecki tiene como grandes influencias a Marx y Rosa Luxemburgo, lo que le confirió cierta ventaja. Ahora bien, es consabido que Kalecki publicó en polaco su obra cumbre los Ensayos sobre la teoría de los ciclos económicos en 1933, tres años antes de la publicación de la Teoría general, lo que refuerza aún más la tesis de Robinson sobre las conexiones de Keynes con los clásicos y Marx. En efecto, las similitudes entre los enfoques neomarxista y estructuralista son mayores de lo que pudiera parecer a primer vista; la teoría del capital monopolista de Baran y Sweezy está radicalmente influenciada por las contribuciones de Kalecki, en tanto que los modelos kaleckianos están sujetos a la teoría de competencia imperfecta u oligopolística, donde los costes marginales son constantes e inferiores a los precios, asimismo, el modelo de Kalecki incide sobre la influencia del grado de monopolio en la formación de precios, es decir, del modelo kaleckiano se desprende la relación defendida por Baran y Sweezy sobre la tendencia creciente de los excedentes (Baran \& Sweezy, 1974). Por tanto, no es de extrañar que ambos enfoques se alejen de la simple noción de crecimiento económico al incidir en la cuestión de la distribución del ingreso; en ambas tradiciones de la economía del desarrollo existe la imperiosa 
obligatoriedad de sustituir las instituciones y el Estado capitalistas, en tanto que comprendían que el Estado moderno representaba uno de los instrumentos más poderosos para perpetuar los intereses de la clase dominante propietaria de los medios de producción. Ergo, cualquier tentativa por presentar un concepto de desarrollo, implica inevitablemente modificar, transformar, e incluso abolir las instituciones capitalistas. De igual manera, el concepto de excedente es importante para ambos enfoques, puesto que conciben la exigencia de incrementar el excedente para su posterior reinversión en medios de producción y fuerza de trabajo que permita aumentar vigorosamente el producto social que consienta la reproducción ampliada de capital. Si bien los objetivos son comunes, existen diferencias hacia dónde y cómo dirigir los esfuerzos desarrollistas; los neomarxistas entienden que el desarrollo de las fuerzas productivas es condición sine qua non para superar el modo de producción capitalista, mientras que los estructuralistas cepalinos ven factible el desarrollo dentro de los límites del capitalismo bajo ciertas condiciones. Ahora bien, ambas tradiciones de la economía del desarrollo no comprenden alcanzar sus objetivos sin romper las relaciones de producción impuestas por las economías del centro. Las estrategias de los estructuralistas para romper las cadenas de la dependencia se encuentran en las transformaciones estructurales que permitan la mejor combinación de los factores productivos, y por ende, proyectar modelos autosostenidos que concurran más allá del mero crecimiento equilibrado anhelado por Nurske. Mientras que para los neomarxistas, las claves para superar el subdesarrollo se hallan en los procesos revolucionarios que permitan abolir los patrones de acumulación capitalista y construir modelos autocentrados de carácter nacional y popular (Amin, 1994).

\section{EL ORIGENDEL SUBDESARROLLO: LAS RAÍCES DEL ATRASO Y LA DICOTOMÍA CENTRO-PERIFERIA}

El origen del subdesarrollo de las naciones de la periferia planteó varias elucidaciones por esclarecer. Los primeros economistas del desarrollo esbozaron elucubraciones sobre qué es el subdesarrollo, y si este, siendo una fase, o etapa, tan solo sería un estado transitorio hasta alcanzar los patrones de consumo y de producción propios de las naciones más industrializadas. El autor quien mejor plasmó este semblante fue el economista estadounidense Rostow en su obra central, Las etapas del crecimiento económico, donde estableció cinco etapas por las que irían transitando los países subdesarrollados hasta alcanzar la quinta etapa definida por él como la fase del consumo a gran escala. No obstante, Furtado no dudó en impugnar las tesis de Rostow, en tanto que consideraba imperativo recabar un alto grado de conocimientos sobre la estructura económica mundial:

Porque disponiendo de esa información, ya no es posible aceptar 
la tesis, que suscriben los autores del estudio, según la cual "en la medida en que el resto de la economía mundial se desarrolla económicamente seguirá básicamente las pautas de consumo de los Estados Unidos". Aceptar esa doctrina implica ignorar la especificidad del fenómeno del subdesarrollo. A ella se debe la confusión entre economía subdesarrollada y "país joven"; y a ella se debe la concepción del desarrollo como una secuencia de fases necesarias, a la Rostow. Captar la naturaleza del subdesarrollo no es tarea fácil: muchas son sus dimensiones y las que son fácilmente visibles no siempre son las más significativas. Pero si algo sabemos con certeza es que el subdesarrollo no tiene nada que ver con la edad de una sociedad o de un país. (Furtado, 1976, p. 22)

Furtado dilucida sobre la fuerte necesidad de llevar a cabo un análisis específico de las causas del subdesarrollo a través del estudio de la historia económica mundial. De este modo, se comprende por qué las escuelas estructuralistas y neomarxista exhiben un fuerte enfoque metodológico histórico-estructural; previsiblemente, el método histórico-estructural característico de ambas escuelas estaría imbuido por el materialismo histórico de Marx, el cual presume el análisis de la totalidad conectada con la historia de la humanidad en constante movimiento transformante, y por tanto, no existe en modo alguno azar en los procesos históricos.
El subdesarrollo no puede concebirse como un estado, sino como un proceso que ocultaría sus raíces en las relaciones de producción propias del capitalismo mundial. No obstante, el análisis histórico de ambos enfoques no es genuinamente el método marxista del materialismo histórico. Con el objeto de desentrañar los orígenes del subdesarrollo, tanto estructuralista como neomarxistas no dudaron en presentar enfoques positivistas para descubrir qué ocultaba el subdesarrollo. Baran, en su obra La economía política del crecimiento, muestra un fuerte método positivista que pretende exponer la influencia de la localización geográfica de las naciones para explicar el proceso de subdesarrollo. En Baran existe cierto determinismo geográfico al suponer patrones similares entre el crecimiento y desarrollo de Inglaterra y Japón. El autor neomarxista ve potentes similitudes entre ambas naciones, tales como la escasez de recursos naturales, el paso del modo de producción feudal al modo de producción capitalista o el hecho de que ambos países son archipiélagos rodeados por el océano.

Empero, estaríamos simplificando el análisis de Baran, debido al hecho de que una de las mayores influencias del autor neomarxista fue el método historicista de Max Weber; la influencia de Weber no se limitó a Baran, sino que también alcanzó a la mayoría de economistas estructuralistas y neomarxistas. E1 neomarxista Herbert Marcuse amplió e incorporó a los estudios neomarxistas el enfoque de Weber sobre el capitalismo y 
la industrialización; la obra de Marcuse, La sociedad industrial y el marxismo, pretende romper con cualquier intento por analizar el proceso del subdesarrollo bajo la influencia del positivismo heredado de Auguste Comte y Émile Dukheim. De este modo, Marcuse enriquece el estudio del proceso del subdesarrollo con las aportaciones de Weber sobre las razones del surgimiento del capitalismo industrial en Europa, abriendo el debate sobre por qué el desarrollo industrial no brotó en el seno de civilizaciones con modos de producción basados en el comercio y los intercambios mercantiles como China e India:

Para Max Weber, existe una suerte de racionalidad que sólo ha aparecido en Occidente, que ha formado o contribuido a formar el capitalismo y que decidirá nuestro futuro previsible. Tratar de captar las manifestaciones múltiples de esta racionalidad, representa una gran parte de la obra de Weber. "El espíritu de capitalismo" -tal como se lo describe en el primer volumen de su Sociología de la Religión- es una de esas manifestaciones: ya el prefacio de esta obra indica, a manera programática, que la racionalidad que va a encamarse en el capitalismo distingue fundamentalmente a la forma occidental de industrialización de todas las demás formas de la economía y de la tecnología. (Marcuse, 1969, p. 10).
El debate sobre las razones por las que surgió antes el capitalismo industrial en Europa que en las naciones de Asia, ha suscitado varias teorías; Baran esclarece que las raíces del atraso se debieron a la expansión colonial de Gran Bretaña y Francia a lo largo y ancho del mundo. El análisis de Baran se centra en el caso particular de la India y cómo la incursión británica fue fatídica para el devenir del país asiático; el autor estadounidense enfatiza que entre los siglos XVIII y XIX, la industria textil más grande del mundo se localizaba en la India, sin embargo, el colonialismo británico no dudó en destruir la industria emblema de la economía india. Baran asevera que las razones de la destrucción de las fuerzas productivas en las colonias tenían como objeto imponer las manufacturas de la metrópoli a la población sometida por el Imperio.

Parece verosímil la explicación de Baran, no obstante, esta relación solo explica el caso de la India. De igual forma, la tesis de Baran dejaría sin esclarecimiento varias experiencias como son las de América Latina, África o China. En el siglo XVIII, Adam Smith reconocía a China como la nación más rica del mundo, sin embargo, su estatus de economía más poderosa del mundo no impedía que la clase trabajadora china se encontrase con dificultades para alcanzar el salario de subsistencia. El pensador neomarxista de origen italiano, Giovanni Arrighi, reconoce en el trabajo de Adam Smith una gran fuente de estudio para comprender las razones de por qué China dejó de ser la mayor economía del mundo. 
En su obra, Adam Smith en Pekin: orígenes y fundamentos del siglo XXI, reproduce el estudio intensivo del economista clásico sobre el estancamiento de la economía de China; Arrighi señala que Adam Smith muestra a China como un país poblado, en el cual su mercado interno era tan grande, o mayor, que el mercado de todas las naciones europeas juntas, y por ende, había sido una economía basada en el comercio que había llegado a su madurez o estado estacionario. No en vano, el economista escocés reconoce en el modo de producción chino la existencia de asimetrías tales como la persistencia de salarios por debajo del precio de los bienes subsistencia, lo que se traducía en una nula capacidad de consumo que permitiese la diversificación de la demanda. Idea esta que parece coincidir con la tesis Furtado al señalar como una de las causas del subdesarrollo la escasa diversificación de la demanda (Furtado, 1976).

Si bien es cierto que el grueso del análisis estructuralista se centró en las causas del subdesarrollo en América Latina, la visión de los estructuralistas no se limitaba al estudio del continente americano, sino que pretendía, desde un análisis que fuese de lo abstracto a lo concreto, especificar las razones del proceso de subdesarrollo a nivel global. Tal como señalaban Prebisch, Furtado, Osvaldo Sunkel o Aníbal Pinto, la hipótesis central partía sobre que el origen del subdesarrollo se encontraba en los aumentos de la productividad media del trabajo, los cuales respondían a la reubicación de los recursos para obtener las máximas ventajas comparativas estáticas en el comercio internacional. De este modo se explica que el progreso técnico permitió el aumento de la productividad del trabajo favorecido por la especialización geográfica, tal como ocurrió en las regiones especializadas en la agricultura tropical o los recursos mineros. Es decir, la especialización productiva creó modelos especializados en la exportación de bienes demandados por las economías de centro, configurando la división internacional del trabajo que abarcó las últimas décadas del siglo XIX y la primera mitad del XX. De igual modo, el excedente de la periferia se dirigía al centro, en tanto que este se lo apropiaban las empresas transnacionales y la clase terrateniente de la periferia; la parte que concentraba en manos de la oligarquía de la periferia se dirigía al consumo improductivo en bienes suntuarios procedentes de las economías del centro, lo que imposibilitaba la reinversión del excedente en medios de producción y fuerza de trabajo. Estas relaciones explicarían, según Furtado, las formaciones sociales identificadas como economías subdesarrolladas; la división internacional del trabajo empujó a las naciones de la periferia a especializarse en los bienes demandados por los centros industriales con el fin de satisfacer las exigencias de divisas para seguir importando bienes de capital de los centros, sin embargo, en muchos casos la especialización se hacía en bienes que no requerían un alto grado de innovación productiva, bloqueando cualquier proceso que facilitase el incremento de la productividad del trabajo. 
Por otro lado, tal como se señaló, el aumento del excedente solo venía a favorecer a una minoritaria clase dominante, la cual en modo alguno podía jugar un papel progresista, sino que más bien se presentaba como una clase reaccionaria y hostil a cualquier proceso reformista orevolucionario. Asimismo, esta élite imitó los patrones de consumo propios de los centros capitalistas e industriales, exteriorizando unas pautas de comportamiento descritas por Thorstein Veblen en la Teoría de la clase ociosa, como la emulación del consumo ostensible, esto es, la clase oligarca de la periferia emulaba los patrones de consumo de la clase burguesa de los centros capitalistas.

No es de extrañar, pues, que a principios de la década de 1950, Hans Singer, junto a Prebisch, denunciasen que el origen del subdesarrollo ocultaba el deterioro de los términos de intercambio. La tesis de Singer-Prebisch venía a confirmar el rechazo en la tesis del beneficio mutuo recogida en el modelo de comercio internacional basado en las ventajas comparativas de Ricardo; el modelo ricardiano de los costes comparativos aludía a la importancia de la especialización productiva en los bienes donde mayor ventaja comparativa poseyesen, al estar esta garantizada por la abundancia de alguno de los factores productivos. Sin embargo, los factores más abundantes en la periferia eran por lo general la fuerza de trabajo y las materias primas; la especialización en procesos intensivos en fuerza de trabajo y materias primas arrojaba un bajo valor añadido, es decir, los países de la periferia se mostraban como modelos primario exportadores y altamente dependientes de las importaciones de bienes de capital y otras manufacturas procedentes del centro a consecuencia de la especialización productiva en bienes primarios. Asimismo, Prebisch denunciaba que el incremento de los precios de las manufacturas era mayor que el incremento de los precios de los bienes primarios y de bajo valor añadido, traduciéndose en la transferencia de renta de los países subdesarrollados a los países desarrollados a través de los precios. El debate sobre el deterioro de los términos de intercambio no tardó en llegar a las filas de los neomarxistas; Arghiri Emmanuel fue quien, con mayor entusiasmo, dedicó sus esfuerzos en analizar la relación de los precios en el intercambio desigual:

Tanto técnica como económicamente, las fluctuaciones de los precios son el producto de la anarquía del sistema capitalista; engendran, como tales, una dilapidación desenfrenada de riquezas. Es un despilfarro como todos los otros despilfarros del capitalismo. Pero las fluctuaciones dañan ambas partes, aunque puede admitirse que dañan más a la parte débil que a la parte fuerte; no pueden, en ningún caso, constituir un mecanismo de transferencia de riquezas de una parte a otra. (Emmanuel, 1972, p. 14)

Por tanto, Emmanuel rechaza la afirmación de Prebisch sobre la 
transferencia de riqueza de la periferia al centro a través de los precios; el análisis de Emmanuel pretende aplicar la teoría valor trabajo de Marx para desentrañar el deterioro de las relaciones de intercambio, para con ello, tomar la explicación sobre cómo el valor de las mercancías se transforma en los precios de producción detallados en el volumen III de El Capital ${ }^{4}$; Emmanuel plantea que el intercambio desigual se debe a las diferencias entre los salarios reales relativos de la periferia y el centro, asimismo, existe perfecta movilidad del factor capital, ergo, las tasas de ganancia ${ }^{5}$ se igualan entre los países del centro y la periferia.

Como los salarios reales relativos de la periferia son más bajos que los de las economías del centro, la tasa de plusvalor es mayor en la periferia, y por ende, existe una transferencia de parte del plusvalor de la periferia al centro, concluyendo que es la propia naturaleza del mercado capitalista la que determina el deterioro de las relaciones de intercambio. Mas el neomarxista Charles Bettelheim, en su Intercambio internacional y desarrollo regional, refuta la concepción del intercambio desigual de Emmanuel; para Bettelheim existe el escenario en donde existen países que presentan el mismo nivel de salarios relativos, sin embargo, exhiben diferentes niveles en la composición orgánica de capital. Por tanto, para Bettelheim el subdesarrollo es resultado del escaso desarrollo de las fuerzas productivas en la periferia, lo que explica la brecha entre los salarios reales relativos de los países de la periferia y el centro. Por otro lado, Samir Amin razona que la comprensión del deterioro de la relaciones de intercambio se encuentra en la aparición, a partir de 1890 , del capitalismo monopolista, el cual ha empujado al alza los precios y el margen de beneficios. Amin establece que los salarios en el centro capitalista se elevaron a partir de la configuración del capitalismo monopolista, lo que dio lugar, en términos de Karl Kautsky y Lenin, a la aristocracia obrera. De este modo, para Amin, la aparición de los monopolios, el imperialismo y la aristocracia obrera explican el deterioro de las relaciones de intercambio.

Por consiguiente, la visión del economista egipcio impugna las tesis de Prebisch y Emmanuel, enfatizando que en el capitalismo periférico el ingreso predominante es la renta de los propietarios de la tierra quienes son, a fin de cuentas, la clase beneficiaria de los intercambios desiguales del comercio internacional. Asimismo, la cuestión de la distribución del producto agrario entre las diferentes clases ha sido una impronta que ha preocupado por igual a estructuralistas y neomarxistas;

\footnotetext{
4 Los precios de producción para Marx se expresan como: $P=c+v+g^{\prime}$, donde c es el capital constante, $v$ el capital circulante y g' la tasa media de ganancia. A diferencia de lo que sugieren varios autores, Marx no pretende con esta relación impugnar la teoría valor trabajo.

5 La tasa de ganancia se calcula como: $p v /(c+v)^{\prime}$ donde pv es la plusvalía, y $(c+v)$ el sumatorio del capital constante (c) y variable (v).
} 
el subdesarrollo, cuyo origen se manifiesta por las relaciones de dependencia entre centro y periferia, encuentra una de sus explicaciones en el sostenimiento de la clase propietaria de la tierra en los países de la periferia. Igualmente, para desentrañar el origen del subdesarrollo, es esencial rastrear en la historia el origen del proceso histórico de la acumulación de capital a escala mundial. Según Immanuel Wallerstein, el proceso de acumulación de capital a escala mundial comenzó en 1501 en Inglaterra y Holanda, a raíz de la entrada masiva de metales preciosos procedentes de América Latina. Por el contrario, Arrighi enfatiza que fueron los reinos de Italia quienes erigieron las precondiciones para la formación y génesis del capitalismo mercantil en el siglo XIII, para, de este modo, dar nacimiento a los patrones de acumulación mercantilistas a través del comercio a lo largo del mediterráneo. La dificultad por situar la génesis del capitalismo no invalida la tesis del origen del capitalismo en Inglaterra y Holanda en el siglo XVI. Las condiciones de ambos países favorecieron la acumulación primaria que posibilitó el surgimiento del capitalismo mercantil, antesala del capitalismo industrial, lo que dio lugar al proceso de acumulación a escala mundial que originó el proceso de subdesarrollo en los países de la periferia. Finalmente, la acumulación de conocimientos sobre el proceso histórico del subdesarrollo permitió a los estructuralistas y neomarxistas identificar las raíces del subdesarrollo, lo que admitió teorizar sobre las estrategias que pudieran superar las barreras para el desarrollo.
BARRERAS PARA EL DESARROLLO: LA ACUMULACIÓN A ESCALA MUNDIAL Y LA NUEVA DIVISIÓN INTERNACIONAL DEL TRABAJO

Ambos enfoques debían comprender cómo se formó el capitalismo industrial en Europa, por lo que encontraron en uno de los discípulos de Furtado, Pierre Salama, la llave para analizar con mayor precisión las relaciones de dependencia y el origen del subdesarrollo. Si bien Salama no es estrictamente un autor neomarxista o estructuralista, su aportación a la teoría de la dependencia es crucial, en tanto que el análisis de Salama se focaliza en la formación del proceso de acumulación de capital a escala mundial, el cual, presumiblemente, tiene su origen en 1501. Sin entrar a analizar el proceso de acumulación primaria que surgió en Inglaterra y Holanda a partir del siglo XVI, la novedad del análisis de Salama enriqueció el estudio de las escuelas estructuralista y neomarxista, que, al mismo tiempo se nutrieron de las aportaciones de Wallerstein y su concepto de sistema mundo. La perspectiva de sistema mundo, o economía mundo, atrajo la atención de varios economistas neomarxistas de la talla de Amin, Arrighi y André Gunder Frank. Por parte de los estructuralistas, figuras como Sunkel y Cardoso, ampliaron sus análisis incorporando la perspectiva del sistema mundo para comprender el proceso de internacionalización de la producción y la configuración de la nueva división internacional del trabajo que comenzó a 
imponerse a finales de las década de 1960 y comienzos de la década de 1970 como resultado de la estrategia de la industrialización orientada a la exportación (IOE). La comprensión del proceso acumulación y circulación de capital a escala mundial, permitió superar las limitaciones del enfoque centro-periferia, al incluir el concepto de Salama de países semindustrializados y el concepto de Wallerstein de la semiperiferia. De este modo, tanto estructuralistas como neomarxistas empezaron a identificar todas las barreras que impedían el desarrollo de las economías de la periferia. Como punto central, ambos enfoques comprendieron que el gran escollo para el desarrollo era el modo de producción capitalista, semblante este que en sus inicios la escuela estructuralista no compartía con el enfoque neomarxista; desde la publicación del primer volumen de El Capital en 1867, los postulados clásicos sobre los automatismos de autorregulación de la economía quedaron en entredicho, en tanto que el análisis dinámico de Marx impugnaba la vieja idea de que "todo los que se produce se consume", o lo que es lo mismo, la "oferta crea su demanda", ergo, nos referimos a la Ley de Say. Marx analizó el capitalismo como un modo de producción cíclico, cuyas contradicciones inherentes lo empujaban inevitablemente a periodos de crisis. En El Capital de Marx se puso de relieve la existencia de crisis de sobreacumulación de capital y sobreproducción de mercancías a consecuencia de las contradicciones inherentes del modo de producción capitalista; Marx, al rechazar el enfoque clásico, señaló que la tendencia de la tasa de ganancia se mostraba decreciente como resultado de los ciclos tecnológicos y el aumento del capital constante dedicado a la inversión de maquinaria en detrimento del capital variable correspondiente a la contratación de la fuerza de trabajo. De este modo, la fuerza de trabajo quedaba condenada al desempleo al engrosar el ejército de reserva industrial, el cual actuaba como un instrumento para disciplinar los salarios en los ciclos alejados de la crisis. Ahora bien, para Marx el trabajo humano abstracto es la fuente del valor, por ende, la fuente del plusvalor es el trabajo vivo, ergo, si el trabajo vivo es sustituido por trabajo muerto la composición orgánica de capital aumentará contrayendo la tasa de ganancia. Aquello tendrá el efecto de movilizar a los capitalistas para llevar a cabo medidas contrarrestantes con el fin de reanimar la tasa de ganancia; estas medidas tendrán el objetivo aumentar la tasa de explotación y revalorizar el capital. Esto es, para revalorizar el capital es necesario emprender la búsqueda de nuevos espacios para la realización del capital. Esto llevará consigo la transformación de estos nuevos espacios de valorización, tal como ocurrió con la periferia al verse subordinada a los intereses de las transnacionales en la década de 1970: Los países industrializados empezaron a experimentar a partir de 1965 el agotamiento del modelo fordista resultado de la crisis de rentabilidad reflejada en la caída de la tasa de ganancia. Ante este escenario, las grandes empresas del centro 
no tardaron en llevar a cabo medidas contrarrestantes que tuvieron como objeto la desvalorización de la fuerza de trabajo y la transformación de la periferia a través de la IOE; el constante aumento de los costes laborales unitarios en el centro empujó a la deslocalización productiva de las transnacionales a las zonas francas en busca de los menores salarios de los países de la periferia. Estas zonas francas se caracterizaban por la ausencia de la aplicación de los marcos laborales y la laxitud impositiva por parte de las instituciones y el Estado. Aquello permitió la internacionalización productiva y la industrialización de la periferia con el objetivo de incrementar la tasa de explotación. Para perpetuar está relación, era condición sine qua non que la clase dominante en la periferia siguiese ejerciendo su papel reaccionario al mostrarse sumisa a los intereses del centro, por lo que nunca podría presentar un papel progresivo. El escollo que representaba la clase dominante de la periferia se materializaba en la cuestión de la tierra, puesto que el sector agrícola era, en muchos casos, el que consentía la existencia de un excedente lo suficientemente grande que pudiese permitir el proceso de acumulación de capital y la redistribución de éste a la inversión productiva. En cambio, éste se dedicaba a garantizar el consumo improductivo de la clase oligarca y la importación de bienes de capital procedentes del centro para acomodar los enclaves industriales subordinados a los intereses de las transnacionales. En efecto, la estrategia de la IOE impuesta por las transnacionales del centro configuró la nueva división internacional del trabajo y fortaleció los efectos de especialización productiva, lo que vino a confirmar las tesis estructuralistas y neomarxistas sobre que la industrialización por sí sola no podía superar el proceso de subdesarrollo.

\section{ESTRATEGIAS PARASUPERAR LAS BARRERAS AL DESARROLLO: DE LA ISI A LA DESCONEXIÓN}

Como se indicó con anterioridad, el estudio exhaustivo por descifrar las raíces del subdesarrollo fue vital para trazar las estrategias de desarrollo, las cuales tenían claras aspiraciones productivistas; los estructuralistas encontraron como primera exigencia acelerar el proceso de acumulación de capital, mientras, los neomarxistas aludían al imperativo por desarrollar las fuerzas productivas y socializar el excedente. Ambos enfoques compartían el mismo objetivo, mas proponían estrategias ligeramente diferentes; cualquier proceso industrializador pasaba por aumentar la productividad en el sector agrario, lo que consentiría el aumento del excedente y liberaría fuerza de trabajo para la industria manufacturera. Para los estructuralistas y los neomarxistas, la cuestión agraria era un punto angular en su análisis; el extraordinario aumento del excedente agrario debía ser, en última instancia, redistribuido por el Estado en forma de inversiones productivas en medios de producción. De este modo, el papel del Estado era fundamental para ambos 
enfoques a la hora de trazar estrategias productivistas que superasen el proceso de subdesarrollo; para los estructuralistas, la reforma agraria debía seguir las pautas de la distribución equitativa de la tierra entre pequeños propietarios, tal como hizo el gobierno reformista de Lázaro Cárdenas en la década de 1930. Por el contrario, los neomarxistas vieron la imperiosa necesidad de colectivizar la tierra como paso para superar el régimen de propiedad capitalista. Para los estructuralistas, aparte de la reforma agraria, el proceso de industrialización debía llevarse a cabo bajo la estrategia de industrialización por sustitución de importaciones (ISI), sin embargo, Prebisch reconocía las limitaciones de la ISI en los países de la periferia, los cuales presentaban unos mercados estrechos y pequeños, resultado de la escasa capacidad de consumo de la clase trabajadora. Asimismo, Kalecki señalaba que la ISI podía tener efectos inflacionistas a consecuencia de los mayores costes de producción de la industria nacional:

En realidad, cualquier reducción de las importaciones o cualquier incremento de las exportaciones, tendrá como contrapartida un incremento de las rentas o una reducción del consumo si la inversión de capital permanece inalterada. Sin embargo, como las importaciones serán sustituidas por producción interior más cara, y el valor de las nuevas exportaciones a las que se pagan primas será menor que las rentas generadas, la presión inflacionista crecerá más que la disminución del superávit de importaciones. Esto se reflejara en el incremento del gasto presupuestario en subvenciones y primas a la exportación. (Kalecki, 1980, p. 154).

De este modo, los neomarxistas se mostraron reticentes a la ISI, planteando la obligatoriedad de llevar a cabo procesos de crecimiento endógeno que focalizasen sus esfuerzos en dotar a los países de la periferia la capacidad de producir sus propios medios de producción. En cierto modo, los estructuralistas también comprendían la exigencia de poder dotarse con los medios de producción propios; Furtado concebía la necesidad de diversificar la producción, y por tanto, diversificar la demanda de consumo. Si no existía un proceso que llevase a cabo la diversificación de la demanda y la producción, los países de la periferia se arriesgaban a caer en procesos productivos intensivos en materias primas y fuerza de trabajo. En cambio, la diversificación permitiría aumentar el uso intensivo del factor capital y la aplicación de tecnología en los procesos productivos que favoreciese incrementos en la productividad del trabajo, lo que generaría un círculo virtuoso, en contraposición al círculo vicioso de la pobreza de Nurske. La única forma de alcanzar este objetivo era a través del aumento de la participación de los ingresos de los trabajadores en la distribución del producto total, ergo, era 
necesario que se llevasen a cabo políticas de distribución de la renta. Para reconciliar este objetivo, tanto estructuralistas como neomarxistas pusieron su punto de mira en la clase dominante. Los neomarxistas proponían expropiar a los propietarios de los medios de producción de la periferia, mientras, los estructuralistas planteaban acentuar la distribución de la renta a través de las instituciones públicas. Para ello, era inevitable que se llevasen a cabo transformaciones estructurales que revirtiesen las relaciones de poder, lo que implica en muchos casos la expropiación o nacionalización de las filiales de las multinacionales en los países de la periferia. Ambos enfoques encontraron en el Estado el instrumento para revertir las relaciones de poder que perpetúan la dicotomía centro-periferia; las estrategias de desarrollo neomarxistas encontraban su sustento en las propuestas de Kalecki, quien no dudó en afirmar que "el camino más racional, y eso sucedería en un sistema socialista, consistiría en aumentar la inversión, lo que aceleraría el desarrollo de la economía“ (Kalecki, 1980, p. 23). Así, para los neomarxistas, como para Kalecki, toda estrategia orbita alrededor del objetivo de elevar la inversión y el consumo de la clase trabajadora a través del gasto público como medida para alcanzar el pleno empleo y la máxima utilización de la capacidad instalada en la industria en un régimen socialista. Es difícil, por tanto, delimitar las diferencias estratégicas entre ambos enfoques de la Economía del desarrollo, en tanto que estructuralistas y neomarxistas destacan por la importancia que otorgan a la demanda agregada y el papel del Estado. Si bien es cierto que los estructuralistas se mostraron desde sus inicios inspirados por la Teoría general de Keynes, no es menos cierto que la escuela neomarxista encontró en la obra de Kalecki un sinfín de herramientas teóricas que ayudaron a enriquecer el análisis sistémico.

\section{CONCLUSIONES}

Tanto estructuralistas como neomarxistas han recibido por parte de sus detractores, críticas hacia el enfoque que proponían. Economistas marxistas como Anwar Shaikh ven una suerte de paralelismo entre las soluciones keynesianas y neomarxistas. Para Shaikh, las propuestas neomarxistas como el modelo autocentrado nacional y popular defendido por Amin, no presenta diferencia alguna con las propuestas nacionalistas e industrializadoras de los economistas cepalinos. Por otro lado, Paul Mattick observa cierta confusión con respecto al papel del Estado para superar el subdesarrollo a través de políticas expansivas de gasto público. Para Mattick, las políticas de gasto público son estériles frente a las contradicciones inherentes del modo de producción capitalista reflejadas en la caída tendencial de la tasa de ganancia. Asimismo, la influencia de economistas poskeynesianos como Piero Sraffa y Joan Robinson, se encuentra por igual en los enfoques estructuralista y neomarxista; el análisis de la competencia imperfecta poskeynesiano no se aleja en demasía de 
la teoría del capitalismo monopolista defendida por los neomarxistas, la cual difiere de la teoría de la competencia real de Marx, pues la teoría marxiana establece que la competencia real entre capitales se caracteriza por el proceso de igualación de las tasas de ganancia entre sectores, mientras que la teoría del capital monopolista postula que los sectores más concentrados gozan de tasas de ganancia superiores a consecuencia del poder de fijación de precios de los monopolios. La discusión sobre si los neomarxistas son marxistas-keynesianos, o los estructuralistas cepalinos keynesianos-marxistas, llevaría inevitablemente a un arduo debate de difícil resolución.

No obstante, como se ha pretendido esclarecer a lo largo del siguiente estudio, existen inevitables conexiones entre las propuestas de la Teoría general de Keynes y el Ensayo sobre los ciclos económico de Kalecki. Sin lugar a dudas, los puentes de unión entre ambas escuelas son mayores que las diferencias que pudieran tener, lo que nos lleva a afirmar que una escuela no hubiera existido como tal sin las aportaciones de la otra. Por tanto, el titánico esfuerzo por desentrañar el origen del proceso del subdesarrollo ha ayudado, a posteriori, a comprender qué es realmente el desarrollo. Ambos enfoques pusieron en duda los planteamientos que han surgido desde los foros de la economía convencional que ahora son hegemónicos desde el ascenso del neoliberalismo, los cuales defienden la posibilidad de alcanzar el desarrollo dentro de los límites del modo de producción capitalista. Sea como fuese, los estructuralistas y los neomarxistas, desde posiciones no siempre radicales, han puesto de relieve la necesidad de plantear el desarrollo desde otros patrones de acumulación, diferentes a los del actual modo de producción capitalista.

\section{Referencias}

1. Amin, S. (1984). La acumulación a escala mundial: crítica de la teoría del subdesarrollo. Madrid: Siglo XXI.

2. Amin, S. (1994). El fracaso del desarrollo en África y en el Tercer Mundo. Madrid: IEPALA.

3. Amin, S. et al. (1972). Imperialismo y comercio internacional: el intercambio desigual. Córdoba: PyP.
4. Arrighi, G. (2007). Adam Smith en Pekin. Orígenes y fundamentos del siglo XXI. Madrid: Akal.

5. Baran, P. A. (1969). La economía política del crecimiento. México D.F: FCE.

6. Baran, P. A. \& Sweezy, P. M. (1974). El capital monopolista. Ensayo sobre el orden económico y social norteamericano. México D.F.: SigloXXI. 
7. Bujarin, N. (1976). El imperialismo y la economía mundial, México D.F: Siglo $\mathrm{XXI}$.

8. Cardoso, F. H. (1977). La originalidad de la copia: la CEPAL y la idea de desarrollo. Revista de la CEPAL, (4).

9. Fröbel, F., Heinrichs, J. \& Kreye, O. (1980), La nueva división inter-nacional del trabajo. Paro estructural en los países industrializados e industrialización de los países en desarrollo, Madrid: Siglo XXI.

10. Furtado, C. (1964). Development and Underdevelopment, Berkeley: Cambridge U.P.

11. Furtado, C. (1976). El desarrollo económico: un mito. Buenos Aires: Siglo XXI.

12. Hirschman, A. O. (1970). La estrategia del desarrollo económico. México, D.F.: FCE.

13. Hirschman, A. O. (1980). Auge y ocaso de la teoría económica del desarrollo. $E l$ Trimestre Económico, México, (188), 1057-1059.

14. Kalecki, M. (1974). El desarrollo de la economía socialista. México, D.F.: FCE.

15. Kalecki, M. (1980). Ensayos sobre las economías en vías de desarrollo. Barcelona: Crítica.

16. Kalecki, M. (1995). Teoría de la dinámica económica. Ensayo sobre los movimientos cíclicos y a largo plazo de la economía capitalista, México D.F.: FCE.
17. Keynes, J. M. (2003). La teoría general de la ocupación, el interés, y el dinero. México D.F.: FCE.

18. Lenin, V. I. (1980). Imperialismo. Etapa superior del capitalismo. Buenos Aires: Sudam.

19. Luxemburgo, R. (1978). La acumulación de capital. Barcelona: Grijalbo.

20. Marcuse, H. (1969). La sociedad industrial y el marxismo. Buenos Aires: Quintaria.

21. Marx, K. (1999). El Capital. Crítica de la economía política, vol. I. México D.F.: FCE.

22. Marx, K. (1999). El Capital. Crítica de la economía política, vol. II. México D.F.: FCE.

23. Marx, K. (1999). El Capital. Crítica de la economía política, vol. III. México, D.F.: FCE.

24. Novack, G. (1965). La ley del desarrollo desigual y combinado. Buenos Aires: Pluma.

25. Nurske, R. (1973). Problemas de la formación del capital en los países insuficientemente desarrollados. México D.F.: FCE.

26. Organización de las Naciones Unidas ONU (1949). Relative prices of exports and imports of underdeveloped countries. Nueva York: ONU.

27. Prebisch, R. (1964). Planteamiento del problema del comercio internacional y el desarrollo. En Nueva política comercial 
para el desarrollo (Informe a la Conferencia de Naciones Unidas sobre Comercio y Desarrollo inaugurada en Ginebra, (23 de marzo de 1964), México, D.F.: FCE.

28. Ramírez, J. M. \& Puerto, L. M. (coord.) (2008). Economía para el desarrollo. Lectura desde una perspectiva crítica. Madrid: La Catarata.

29. Ricardo, D. (1973). Principios de economía política y tributación. Madrid: Hora $\mathrm{H}$.

30. Robinson, J. (1946). La economía de la competencia imperfecta. Madrid: Aguilar.

31. Robinson, J. (1968). Ensayo sobre economía marxista. México D.F.: Siglo XXI.

32. Rostow, W. W. (1967). El proceso de crecimiento económico. Madrid: Alianza.

33. Rostow, W. W. (1990). Theorists of economic growth from David Hume to the present. Nueva York: Oxford University Press.
34. Salama, P. (1976). El proceso de subdesarrollo. Ensayo sobre los límites de acumulación nacional de capital en las economías semindustrializadas. MéxicoD.F.: Era.

35. Shaikh, A. (2006). Valor, acumulación y crisis. Buenos Aires: Razón y Revolución.

36. Shaikh, A. (2009). Teorías del comercio internacional. Madrid: Maia.

37. Singer, H. W. (1981). Estrategia del desarrollo internacional. Ensayos sobre el atraso económico, México D.F.: FCE.

38. Smith, A. (1996). La riqueza de las naciones. (Libros I-II-III y selección de los Libros $I V y$ V). Madrid: Alianza.

39. Veblen, T. (2002). La teoría de la clase ociosa. Madrid: FCE.

40. Wallerstein, I. (1979). The capitalist world-economy. Cambridge: Cambridge University.

41. Wallerstein, I. (1988). El capitalismo histórico. Madrid: Siglo XXI. 